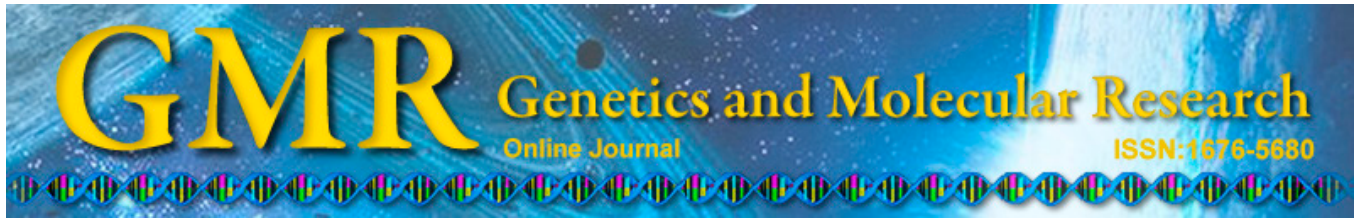

\title{
MicroRNA profiling in cutaneous wounds of diabetic rats
}

\author{
Y.-F. Liu ${ }^{1,2}$, M. Ding², D.-W. Liu ${ }^{1}$, Y. Liu ${ }^{1}$, Y.-G. Mao ${ }^{1}$ and Y. Peng ${ }^{1}$ \\ ${ }^{1}$ First Affiliated Hospital of Nanchang University, Nanchang, China \\ ${ }^{2}$ Guangzhou Integrated Traditional Chinese and Western Medicine Hospital, \\ Guangzhou, China \\ Corresponding author: D.-W. Liu \\ E-mail: dewuliu@126.com
}

Genet. Mol. Res. 14 (3): 9614-9625 (2015)

Received January 7, 2015

Accepted May 25, 2015

Published August 14, 2015

DOI http://dx.doi.org/10.4238/2015.August.14.24

\begin{abstract}
Despite years of effort, current therapies for diabetic wounds are still not fully efficacious. Emerging evidence has suggested that microRNAs (miRNAs) play key roles in multiple physiological and pathological processes in eukaryotes, and could potentially be powerful therapeutic tools. This study investigated the differential expression profiling of miRNAs in cutaneous wounds in streptozotocininduced diabetic rats and normal rats, and its significance in diabetic wound healing. Using microarrays, 18 miRNAs were identified as being upregulated and 65 as being downregulated in the diabetic group. The miRNA profiling results were validated by quantitative reverse transcriptase polymerase chain reaction. Finally, functional annotation analysis using the DAVID and miR2Subpath databases revealed that the differentially expressed miRNAs were involved in MAPK signaling pathways, the Wnt signaling pathway, and other signaling pathways that may be closely linked to wound healing. This study provides an experimental foundation for further investigation of mechanisms that underlie poor diabetic wound healing, and of miRNA-based therapies that are associated with wound healing.
\end{abstract}

Key words: Diabetes mellitus, experimental; Skin; Wound healing; MicroRNA profiling 


\section{INTRODUCTION}

Diabetes mellitus is increasingly prevalent. Previous studies have established that the ability to heal wounds is severely impaired in diabetic patients (Morain and Colen, 1990), and poor wound healing can result in morbidity or death. Although significant progress has been made, the current therapeutic approaches are still not effective (Cavanagh et al., 2005), and the economic burden of the treatment is great. Hence, there is a need for a better understanding of the mechanisms that underlie this diabetic complication, in order to develop therapies that are more effective.

MicroRNAs (miRNAs) are short non-coding RNAs and can efficiently induce posttranscriptional gene repression, which renders them a potentially powerful therapeutic tool. It is estimated that they can target over 1000 human miRNAs and about $60 \%$ of human protein-coding genes (Bartel, 2009), and are involved in almost all of the signal transduction pathways. Recent evidence has indicated that miRNAs play key roles in multiple physiological and pathological processes in eukaryotes, such as stage development, organ development, cell differentiation, signal transduction, metabolism, and tumorigenesis. Consequently, numerous investigators have attempted to ascertain their relevance in disease in order to develop miRNA-based therapies, which restore the molecular and cellular processes required for successful healing. Several miRNAs are specifically expressed in the skin and its appendages (Yi et al., 2006; Aberdam et al., 2008), and some of them are closely related to wound healing (Banerjee and Sen, 2013). However, few studies have been conducted on diabetic wound healing.

In this study, we explored the differential expression profiling of miRNAs in cutaneous wounds in streptozotocin (STZ)-induced diabetic rats and normal rats using miRNA microarray assays, and investigated the mechanism that underlies poor diabetic wound healing in order to provide a theoretical and experimental foundation for future studies.

\section{MATERIAL AND METHODS}

\section{Diabetic rat model and sample harvest}

All of the animal studies were conducted in accordance with a protocol approved by the Institutional Review Board of Nanchang University. Young male Sprague-Dawley rats (weighing 180-200 g) were obtained from the Laboratory Animal Center of Nanchang University, and housed in an environmentally controlled facility on a 12-h light/dark cycle. A week later, six rats (weighing 230-250 g) were randomly selected for induction of the STZ-induced type 1 diabetic model, by intraperitoneal injection of a single dose of STZ (Sigma-Aldrich, St. Louis, MO, USA) at $65 \mathrm{mg} / \mathrm{kg}$ body weight in $50 \mathrm{mM}$ citrate buffer, $\mathrm{pH} 4.0$ (Group A). Six control animals received an equal volume of citrate buffer (Group B). Blood glucose levels were measured on $3,7,14,21$, and 28 days after injection, and food and water intake, as well as the animals' health, were monitored throughout the study. Animals with blood glucose levels exceeding $300 \mathrm{mg} / \mathrm{dL}$ were deemed diabetic and were used in the study. Four weeks after the onset of diabetes, the animals were anesthetized and the dorsal hair was clipped and depilated. Dorsal skin was marked with a standardized template $\left(3.14 \mathrm{~cm}^{2}\right)$ and excised to create a full-thickness dorsal excisional wound. After surgery, wounds were covered with normal dressings that were changed daily, using only physiological saline to clean the wounds. All of the rats were housed separately and provided with free access to water and standard rodent chow. On day 3 , the 
wound tissue was harvested and dissected, and then equal amounts of it from the same group were pooled, immediately immersed in liquid nitrogen, and stored at $-80^{\circ} \mathrm{C}$ until use.

\section{RNA isolation and microarray experiment}

The total RNAs were extracted from the samples using TRIzol reagent (Invitrogen, Grand Island, NY, USA) according to the manufacturer protocol, and quantified by spectrophotometry (NanoDrop ND-1000, Wilmington, DE, USA). RNA quality was assessed by formaldehyde-denaturing gel electrophoresis. Total RNA was purified using the mirVana ${ }^{\mathrm{TM}}$ miRNA isolation kit (Ambion, Austin, TX, USA) and quantified again. A total of 200 ng purified RNA was labeled with fluorescein $\mathrm{Cy} 3$, and hybridization was conducted using an Agilent Rat miRNA 8X15K microarray (Agilent Technologies, Santa Clara, CA, USA), which provides full coverage of all known rat miRNAs (677 unique mature miRNAs, based on miRBase V. 16.0, http://www. mirbase.org), according to manufacturer protocol. After the microarray slides were washed, hybridization signals were detected by scanning the slides. Data were extracted using Agilent Feature Extraction Software V. 10.7, normalized using the Agilent GeneSpring GX 10.0 software, and differences between the groups were analyzed. miRNAs were considered to be differentially expressed if they exhibited more than a two-fold expression difference between the two groups.

\section{Quantitative reverse transcriptase polymerase chain reaction (qRT-PCR) for miRNA expression analysis}

To validate the miRNA microarray data, rno-miR-150 and rno-miR-31 were selected for qRT-PCR assays using fluorescent nucleic acid dye (SYBR ${ }^{\circledR}$ Green I) on a 7900HT Fast Real-Time PCR System (Applied Biosystems), and snRNA U6 was selected as the normalization control. All of the primers (miRNA RT primer and PCR primers) were synthesized by Invitrogen (Table 1). Briefly, $100 \mathrm{ng}$ of the purified total RNA was reverse transcribed under the following conditions: $16^{\circ} \mathrm{C}$ for $10 \mathrm{~min}, 37^{\circ} \mathrm{C}$ for $30 \mathrm{~min}$, and $65^{\circ} \mathrm{C}$ for $5 \mathrm{~min}$. The conditions for the PCR were as follows: $95^{\circ} \mathrm{C}$ for $10 \mathrm{~min}$, followed by 40 cycles at $95^{\circ} \mathrm{C}$ for $15 \mathrm{~s}$ and $60^{\circ} \mathrm{C}$ for $1 \mathrm{~min}$. All of the reactions were run in triplicate. A melting curve analysis was performed at $60^{\circ}-95^{\circ} \mathrm{C}$, temperature ramp $2 \%$. Subsequently, $2-4 \mu \mathrm{L}$ miRNA of the real time PCR products were used to confirm the specificity of the RT-PCR by $1.5 \%$ nondenaturing-agargel electrophoresis. The relative expression level of each miRNA, which was represented as a crossing threshold (Ct), was calculated using the following equation: $2^{-\Delta \mathrm{Ct}}$, where $\Delta \mathrm{Ct}=\mathrm{Ct}_{\text {miRNA }}-\mathrm{Ct}_{\mathrm{U} 6}$. The fold change of each miRNA was calculated using the equation $2^{-\Delta \Delta \mathrm{Ct}}$.

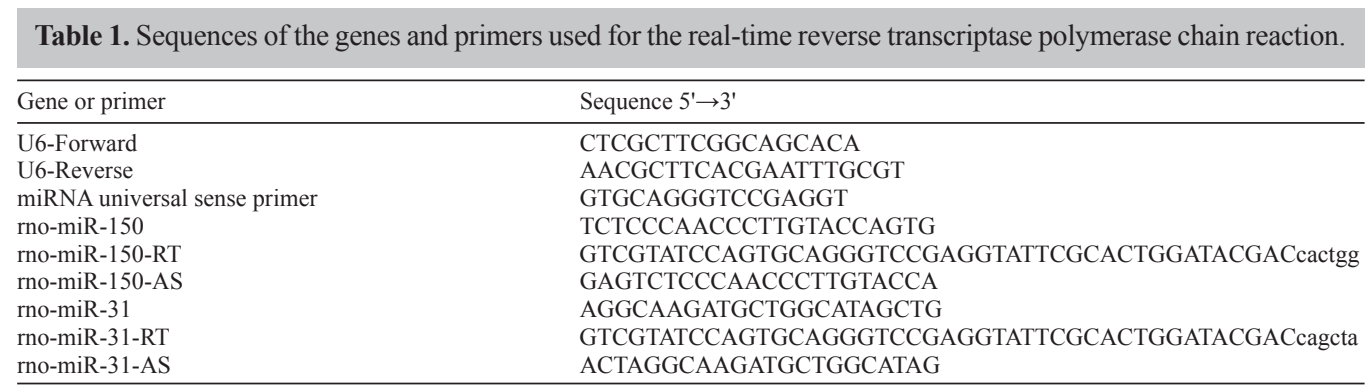




\section{Functional annotation and pathway analysis}

To understand the functions of the differentially expressed miRNAs, we identified the target genes of the miRNAs by integrating three public databases (TargetScan, miRDB, and miRanda). The target genes were then annotated by KEGG pathway enrichment analysis using the DAVID database (http://david.abcc.ncifcrf.gov/home.jsp) (Huang et al., 2009a,b). In addition, we performed pathway enrichment analysis using the miR2Subpath database (http://202.97.205.78:8080/miR2Subpath/index.jsp), which considers a miRNA as a regulator of a signaling pathway if the miRNA target genes are significantly enriched in the signaling pathway $(\mathrm{P}<0.001)$. We then identified several signaling pathways that are implicated in wound healing and some of the differentially expressed miRNAs that are involved in these signaling pathways. Finally, we performed a PubMed (http://www.ncbi.nlm.nih.gov/pubmed/) literature search using "miRNA" as a key word, in order to retrieve all relevant publications and compile a list of known functions of the miRNAs.

\section{RESULTS}

\section{Diabetic rat phenotype}

The experimental rats became hyperglycemic three days after STZ injection, and remained hyperglycemic (blood glucose levels exceeding $426.6 \mathrm{mg} / \mathrm{dL}$ at each time point) before being killed for tissue harvesting. Water intake was approximately $280 \mathrm{~mL} /$ day, food intake was about $56 \mathrm{~g} /$ day, and body weight averaged $290 \mathrm{~g}$ on the day of surgery. The same parameters for the control group were approximately $50 \mathrm{~mL} /$ day, $45 \mathrm{~g} /$ day, and $410 \mathrm{~g} / \mathrm{rat}$, respectively. The experimental rats were significantly thinner and smaller than the control rats, and had matted and withered coats (Figure 1).

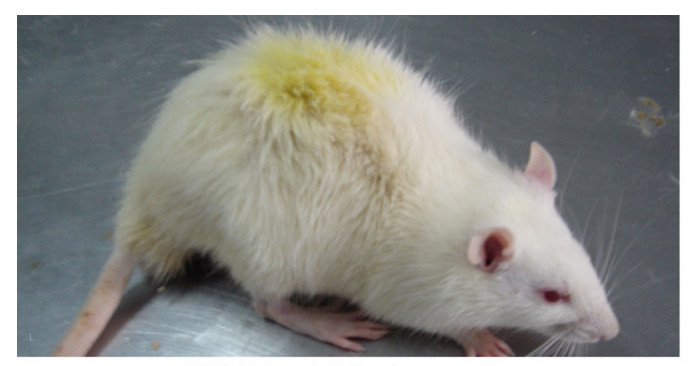

STZ-induced diabetic rat

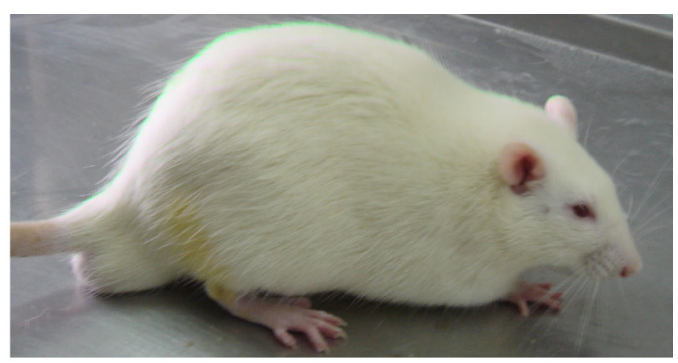

normal rat

Figure 1. Phenotypes of streptozotocin-induced diabetic and control rats.

\section{Total RNA quality}

The purities, concentrations, and weights of the total RNAs all met the experimental requirements (Table 2). An electropherogram of the formaldehyde-denaturing gel electrophoresis indicated that the electrophoretic strips were clear and that the strip brightness of 28S:18S rRNA approached 2:1, suggesting good integrity. 
Table 2. Quality of the total RNA in cutaneous wound tissue isolated from streptozotocin-induced diabetic rats and control rats.

\begin{tabular}{lcccc}
\hline Group & Total amount $(\mu \mathrm{g})$ & A260/280 & A260/230 & Concentration $(\mu \mathrm{g} / \mu \mathrm{L})$ \\
\hline A & 95.6 & 1.93 & 1.73 & 1.249 \\
B & 54.0 & 1.91 & 1.22 & 0.716 \\
\hline
\end{tabular}

\section{miRNA expression profiling in cutaneous wounds of STZ-induced diabetic and control rats}

Scanned images of the hybridized miRNA microarray of the STZ-induced diabetic and control rats are shown in Figure 2. Eighty-three miRNAs were identified, 18 of which were upregulated (Table 3 ) and 65 were downregulated (Table 4) in diabetic cutaneous wounds. A scatter plot of the fluorescence ratio was generated to visualize the differentially expressed miRNAs (Figure 3).

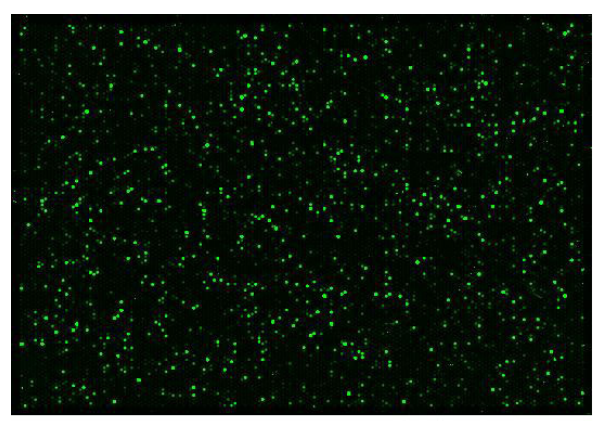

experimental group

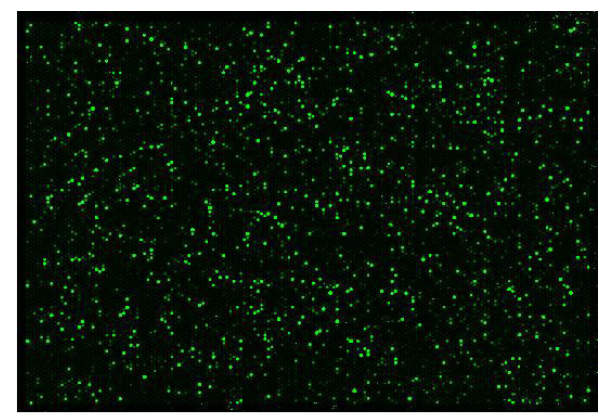

control group

Figure 2. Scanned images of the hybridized microarray of miRNAs in cutaneous wounds of streptozotocin-induced diabetic and control rats.

Table 3. Upregulated miRNAs detected in cutaneous wounds of streptozotocin-induced diabetic rats.

\begin{tabular}{lcccr}
\hline miRNA & miRBase accession No.* & Total probe signal (A) & Total probe signal (B) & Fold change (A vs B) \\
\hline rno-miR-496-5p & MIMAT0017372 & 71.0868 & 0.1 & 1049.6483 \\
rno-miR-105 & MIMAT0012825 & 43.6151 & 0.1 & 644.0087 \\
rno-miR-466c-5p & MIMAT0005279 & 31.6145 & 0.1 & 466.8112 \\
rno-miR-122-5p & MIMAT0000827 & 29.675 & 0.1 & 438.1729 \\
rno-miR-331-5p & MIMAT0017033 & 21.4106 & 0.1 & 316.1431 \\
rno-miR-338-5p & MIMAT0004646 & 8.90167 & 0.1 & 131.4397 \\
rno-miR-674-5p & MIMAT0005329 & 8.78381 & 0.1 & 129.6994 \\
rno-miR-539-5p & MIMAT0003176 & 104.0009 & 31.98064 & 4.8018 \\
rno-miR-297 & MIMAT0000899 & 55.8271 & 20.18888 & 4.0831 \\
rno-miR-466d & MIMAT0017824 & 503.926 & 205.12729 & 3.6274 \\
rno-miR-465-5p & MIMAT0012850 & 252.347 & 132.6893 & 2.8081 \\
rno-miR-672-5p & MIMAT0005327 & 739.271 & 414.651 & 2.6325 \\
rno-miR-3593-5p & MIMAT0017896 & 24.6128 & 47.6116 & 2.4872 \\
rno-miR-32-3p & MIMAT0017103 & 785.362 & 803.567 & 2.4652 \\
rno-miR-466b-5p & MIMAT0005278 & 1279.352 & 36.148 & 2.3508 \\
rno-miR-382-5p & MIMAT0003201 & 54.708 & 232.0625 & 2.2347 \\
rno-miR-150-5p & MIMAT0000853 & 349.40732 & 33.947838 & 2.0336 \\
rno-miR-30c-1-3p & MIMAT0004719 & 46.7544 & & \\
\hline
\end{tabular}

*http://www.mirbase.org/. 
Table 4. Downregulated miRNAs detected in cutaneous wounds of streptozotocin-induced diabetic rats.

\begin{tabular}{|c|c|c|c|c|}
\hline miRNA & miRBase accession No.* & Total probe signal (A) & Total probe signal (B) & Fold change (B vs A) \\
\hline rno-miR-196a-5p & MIMAT0000871 & 0.1 & 84.9508 & 575.3241 \\
\hline rno-miR-134-5p & MIMAT0000840 & 0.1 & 52.8724 & 358.0749 \\
\hline rno-miR-425-3p & MIMAT0017306 & 0.1 & 48.446198 & 328.0988 \\
\hline rno-miR-484 & MIMAT0005319 & 0.1 & 47.28 & 320.2008 \\
\hline rno-miR-31-3p & MIMAT0017102 & 0.1 & 46.9324 & 317.8467 \\
\hline rno-miR-328a-3p & MIMAT0000564 & 0.1 & 44.155098 & 299.0376 \\
\hline rno-miR-96-5p & MIMAT0000818 & 0.1 & 43.4803 & 294.4677 \\
\hline rno-miR-338-3p & MIMAT0000581 & 0.1 & 43.024002 & 291.3773 \\
\hline rno-miR-218a-5p & MIMAT0000888 & 0.1 & 42.9384 & 290.7977 \\
\hline rno-miR-3564 & MIMAT0017837 & 0.1 & 41.9004 & 283.7678 \\
\hline rno-miR-878 & MIMAT0005286 & 0.1 & 41.6103 & 281.8032 \\
\hline rno-miR-204-5p & MIMAT0000877 & 0.1 & 37.277 & 252.4561 \\
\hline rno-miR-466b-1-3p & MIMAT0017285 & 0.1 & 36.74054 & 248.8230 \\
\hline rno-miR-378a-5p & MIMAT0003378 & 0.1 & 35.0034 & 237.0583 \\
\hline rno-miR-455-5p & MIMAT0005316 & 0.1 & 34.5202 & 233.7859 \\
\hline rno-miR-30a-3p & MIMAT0000809 & 0.1 & 33.589897 & 227.4854 \\
\hline rno-miR-743a-3p & MIMAT0005334 & 0.1 & 32.1871 & 217.9851 \\
\hline rno-miR-222-3p & MIMAT0000891 & 0.1 & 31.817799 & 215.4840 \\
\hline rno-miR-542-3p & MIMAT0003179 & 0.1 & 31.7279 & 214.8752 \\
\hline rno-miR-532-3p & MIMAT0005323 & 0.1 & 31.4367 & 212.9031 \\
\hline rno-miR-335 & MIMAT0000575 & 0.1 & 29.2803 & 198.2990 \\
\hline rno-miR-346 & MIMAT0000596 & 0.1 & 28.90421 & 195.7519 \\
\hline rno-miR-341 & MIMAT0000587 & 0.1 & 28.5619 & 193.4337 \\
\hline rno-miR-1188-5p & MIMAT0017854 & 0.1 & 27.9521 & 189.3038 \\
\hline rno-miR-3557-3p & MIMAT0017820 & 0.1 & 27.7546 & 187.9663 \\
\hline rno-miR-322-3p & MIMAT0000547 & 0.1 & 23.0238 & 155.9272 \\
\hline rno-miR-144-3p & MIMAT0000850 & 0.1 & 21.9334 & 148.5426 \\
\hline rno-miR-423-5p & MIMAT0017305 & 0.1 & 21.7068 & 147.0079 \\
\hline rno-miR-678 & MIMAT0012857 & 0.1 & 21.45811 & 145.3237 \\
\hline rno-miR-331-3p & MIMAT0000570 & 0.1 & 20.6477 & 139.8352 \\
\hline rno-miR-542-5p & MIMAT0003178 & 0.1 & 20.0021 & 135.4630 \\
\hline rno-miR-127-3p & MIMAT0000833 & 0.1 & 19.827 & 134.2771 \\
\hline rno-miR-363-3p & MIMAT0003210 & 0.1 & 19.1364 & 129.6001 \\
\hline rno-miR-449a-59 & MIMAT0001543 & 0.1 & 18.7991 & 127.3157 \\
\hline rno-miR-200c-3p & MIMAT0000873 & 0.1 & 18.1336 & 122.8087 \\
\hline rno-miR-30e-3p & MIMAT0004720 & 0.1 & 17.7143 & 119.9690 \\
\hline rno-miR-362-5p & MIMAT0012828 & 0.1 & 17.488 & 118.4364 \\
\hline rno-miR-186-5p & MIMAT0000863 & 0.1 & 17.4838 & 118.4079 \\
\hline rno-miR-379-5p & MIMAT0003192 & 0.1 & 16.0689 & 108.8256 \\
\hline rno-miR-34b-5p & MIMAT0000813 & 0.1 & 15.8732 & 107.5002 \\
\hline rno-miR-434-3p & MIMAT0005315 & 0.1 & 14.9947 & 101.5507 \\
\hline rno-miR-291a-3p & MIMAT0000895 & 0.1 & 14.8156 & 100.3377 \\
\hline rno-miR-182 & MIMAT0005300 & 0.1 & 14.4833 & 98.0872 \\
\hline rno-miR-154-5p & MIMAT0000856 & 0.1 & 14.0399 & 95.0843 \\
\hline rno-miR-34c-5p & MIMAT0000814 & 0.1 & 13.8955 & 94.1064 \\
\hline rno-miR-877 & MIMAT0005285 & 0.1 & 13.60205 & 92.1190 \\
\hline rno-miR-192-5p & MIMAT0000867 & 0.1 & 13.4023 & 90.7662 \\
\hline rno-miR-493-3p & MIMAT0003191 & 0.1 & 13.3178 & 90.1940 \\
\hline rno-miR-667-3p & MIMAT0012852 & 0.1 & 12.64 & 85.6036 \\
\hline rno-miR-181a-1-3p & MIMAT0000884 & 0.1 & 12.2416 & 82.9055 \\
\hline rno-miR-3561-5p & MIMAT0017830 & 0.1 & 11.9473 & 80.9123 \\
\hline rno-miR-328b-3p & MIMAT0017904 & 0.1 & 11.9015 & 80.6022 \\
\hline rno-miR-674-3p & MIMAT0005330 & 0.1 & 9.0774 & 61.4761 \\
\hline rno-miR-339-3p & MIMAT0004648 & 0.1 & 8.38338 & 56.7759 \\
\hline rno-miR-351-5p & MIMAT0000608 & 0.1 & 7.55103 & 51.1389 \\
\hline rno-miR-191-3p & MIMAT0017146 & 0.1 & 6.99531 & 47.3753 \\
\hline rno-miR-23a-5p & MIMAT0004712 & 0.1 & 6.68763 & 45.2916 \\
\hline rno-let-7d-3p & MIMAT0000563 & 0.1 & 6.10358 & 41.3361 \\
\hline rno-miR-31-5p & MIMAT0000810 & 27.0221 & 206.66501 & 5.1796 \\
\hline rno-miR-770-3p & MIMAT0017317 & 18.7092 & 117.31551 & 4.2466 \\
\hline rno-miR-125a-3p & MIMAT0004729 & 10.038 & 51.37843 & 3.4664 \\
\hline rno-miR-503-5p & MIMAT0003213 & 32.4069 & 154.1989 & 3.2225 \\
\hline rno-miR-196b-5p & MIMAT0001082 & 21.3282 & 88.2556 & 2.8024 \\
\hline rno-miR-450a-5p & MIMAT0001547 & 18.0602 & 55.8997 & 2.0962 \\
\hline rno-miR-874-3p & MIMAT0005284 & 10.7577 & 32.6481 & 2.0553 \\
\hline
\end{tabular}

*http://www.mirbase.org/. 


\section{Log-Log Scatter Plot}

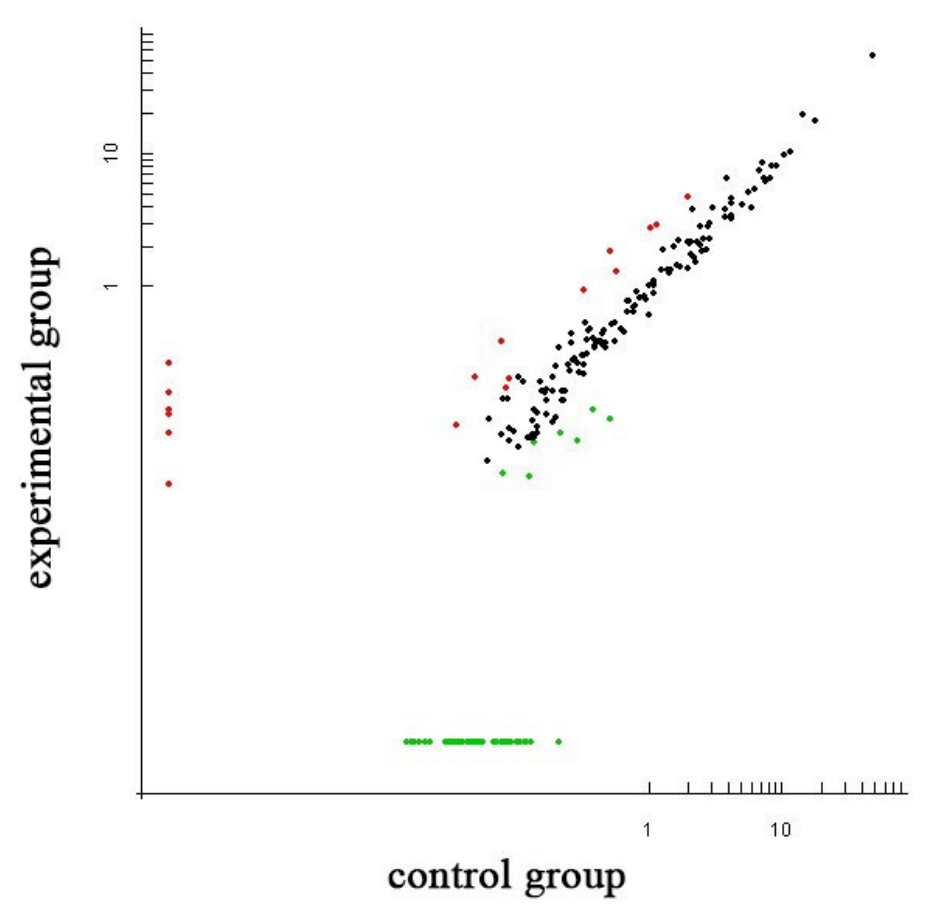

Figure 3. Scatter plot for fluorescence signal intensity of the miRNAs in two samples. Both axes represent the fluorescence signal intensity of the miRNAs in chips, and each point represents the fluorescence signal intensity of one probe set (miRNA). Red points indicate an $\mathrm{A}: \mathrm{B}$ ratio $\geq 2$ (upregulated genes), green points indicate an $\mathrm{A}: \mathrm{B}$ ratio $\leq 0.5$ (downregulated genes), and black points indicate A:B ratios that were between 0.5 and 2 .

\section{Verification of the microarray data by qRT-PCR}

To verify our array results, we performed qRT-PCR assays on selected miRNAs (rnomiR-150 and rno-miR-31) from the STZ-induced diabetic rats and controls (three times each). Amplification and dissociation curve charts for rno-miR-150, rno-miR-31, and snRNA U6 were generated (Figure 4), and $1.5 \%$ nondenaturing-agargel electrophoresis was performed to evaluate the RT-PCR. The qRT-PCR data revealed that rno-miR-150 increased by up to 2.63 -fold more in diabetic wound tissue than in normal wound tissue, whereas rno-miR-31decreased by 3.64-fold. These results are similar to the differential expression detected by the array analysis, and demonstrate that miRNAs were significantly upregulated or downregulated in the diabetic wound tissue in comparison with the normal wound tissue $(\mathrm{P}<0.005$; Figure 5). The dissociation curve chart shows that all of the curves were unimodal, indicating the specificity of the amplified product. The $1.5 \%$ nondenaturing-agar gel electrophoresis revealed that all of the electrophoretic bands of the RT-PCR products were clear, and the length of all of the RT-PCR products was approximately $100 \mathrm{bp}$. All of these data suggest that the results of the RT- PCR were accurate. 

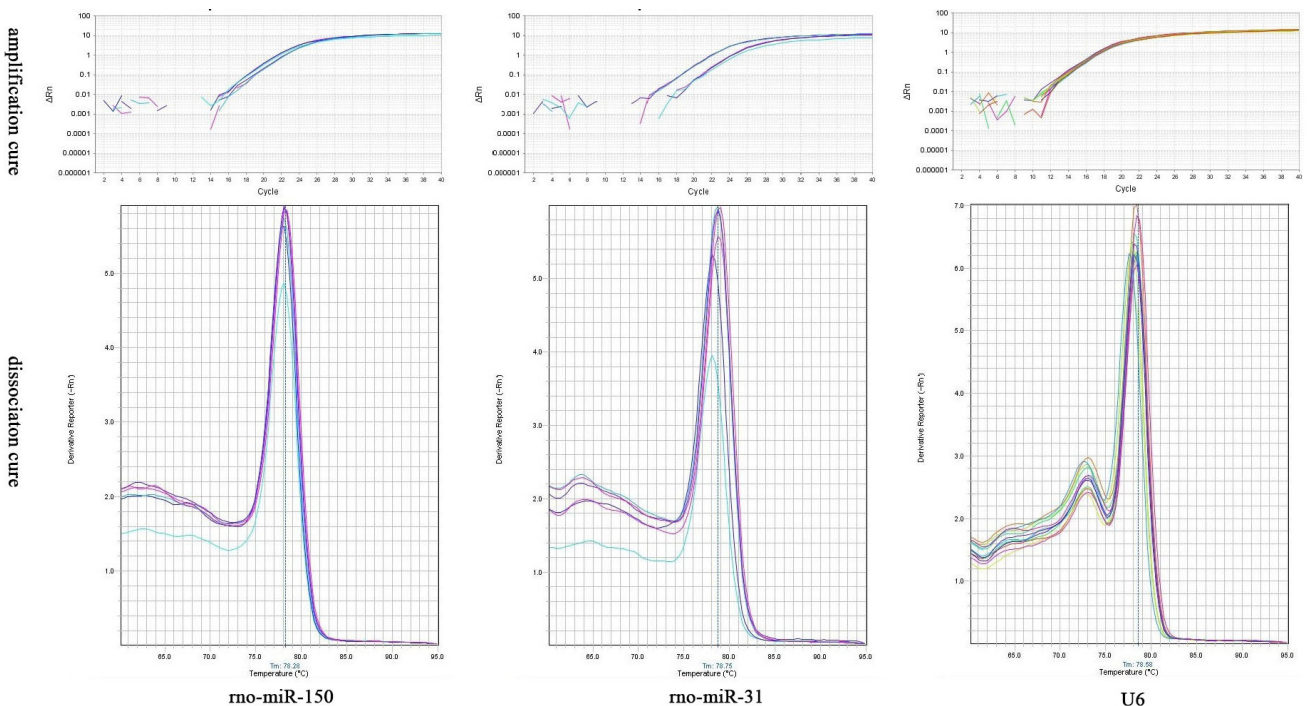

U6

Figure 4. Amplification and dissociation curve charts for rno-miR-150, rno-miR-31, and snRNA U6. In the amplification curve chart, the $\mathrm{x}$-axis represents cycle number and the $\mathrm{y}$-axis represents the real-time fluorescence signal intensity of the corresponding cycle number. In the dissociation curve chart, the $\mathrm{x}$-axis represents the temperature of the reverse transcriptase polymerase chain reaction (RT-PCR) products and the y-axis represents the real-time fluorescence-signal-intensity change rate with increasing temperature. Differently colored curves correspond to different RT-PCRs.
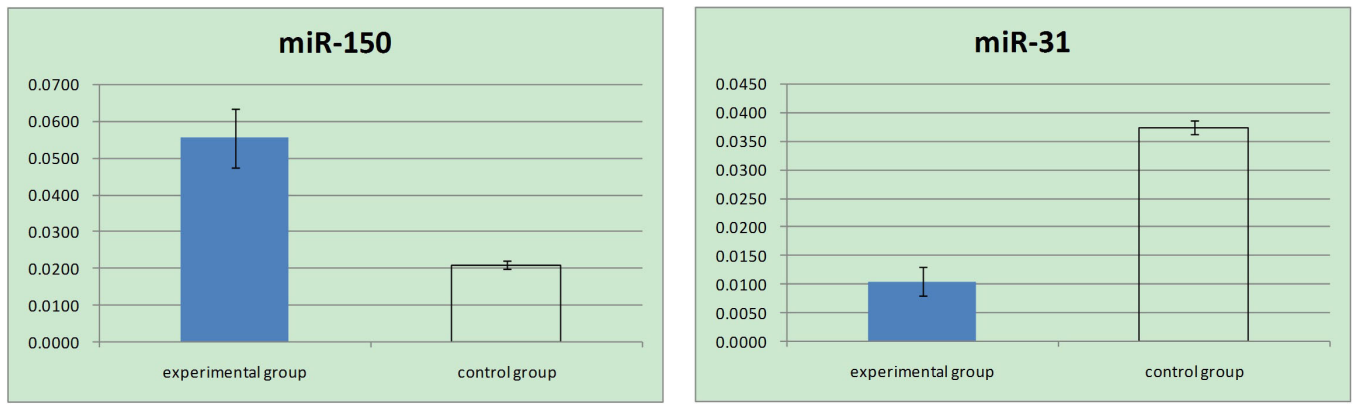

Figure 5. Relative expression levels of miR-150 (A) and miR-31 (B) in cutaneous wound tissue isolated from streptozotocin-induced diabetic rats (filled bars, $\mathrm{N}=3$ ) and control rats (open bars, $\mathrm{N}=3$ ) by quantitative reverse transcriptase polymerase chain reaction, normalized to snRNA U6, and calculated using the following equation: $2^{-\Delta \mathrm{Ct}}$, where $\Delta \mathrm{Ct}=\mathrm{Ct}_{\text {miRNA }}-\mathrm{Ct}_{\mathrm{U} 6}$. Values are reported as means $\pm \mathrm{SDs}$.

\section{Functional annotation and pathway analysis}

In all, 835 target genes of the differentially expressed miRNAs were obtained, according to the criterion that targets predicted by all three public databases were considered putative candidates. The results of the enrichment analysis revealed that 20 KEGG pathways were significantly enriched $(\mathrm{P}<0.05)$, and the MAPK signaling pathway was the most enriched 
(Table 5). Pathway enrichment analysis using the miR2Subpath database revealed that several signaling pathways that are associated with wound healing were enriched, and some of the differentially expressed miRNAs were involved in these pathways (Table 6).

Table 5. Predicted functions of differentially expressed miRNA target genes.

\begin{tabular}{lccc}
\hline KEGG pathway & Count & $\%$ & P value \\
\hline MAPK signaling pathway & 31 & 4.6 & $7.00 \mathrm{E}-06$ \\
Adipocytokine signaling pathway & 12 & 1.8 & $2.70 \mathrm{E}-04$ \\
Oocyte meiosis & 15 & 2.2 & $7.10 \mathrm{E}-04$ \\
Long-term potentiation & 11 & 1.6 & $1.10 \mathrm{E}-03$ \\
Colorectal cancer & 11 & 1.5 & $4.70 \mathrm{E}-03$ \\
Pancreatic cancer & 10 & 1.3 & $5.00 \mathrm{E}-03$ \\
Amyotrophic lateral sclerosis & 9 & 2.1 & $6.40 \mathrm{E}-03$ \\
Neurotrophin signaling pathway & 14 & 1.3 & $6.60 \mathrm{E}-03$ \\
Long-term depression & 9 & 2.4 & $1.30 \mathrm{E}-02$ \\
Chemokine signaling pathway & 16 & 1.9 & $1.60 \mathrm{E}-02$ \\
Cell cycle & 13 & 1.5 & $1.60 \mathrm{E}-02$ \\
TGF-beta signaling pathway & 10 & 2.5 & $2.00 \mathrm{E}-02$ \\
Cytokine-cytokine receptor interaction & 17 & 1.5 & $2.50 \mathrm{E}-02$ \\
Prostate cancer & 10 & 1.6 & $2.60 \mathrm{E}-02$ \\
T cell receptor signaling pathway & 11 & 1.5 & $3.40 \mathrm{E}-02$ \\
GnRH signaling pathway & 10 & 1.2 & $3.40 \mathrm{E}-02$ \\
p53 signaling pathway & 8 & 1.3 & $3.60 \mathrm{E}-02$ \\
ECM-receptor interaction & 9 & 1.9 & $3.80 \mathrm{E}-02$ \\
Wnt signaling pathway & 13 & 1.3 & $4.30 \mathrm{E}-02$ \\
Apoptosis & 9 & $4.80 \mathrm{E}-02$ \\
\hline
\end{tabular}

Table 6. KEGG pathways implicated in wound healing and involving differentially expressed miRNAs.

\begin{tabular}{|c|c|c|}
\hline KEGG pathway & Wound healing-related functions* & miRNAs involved \\
\hline MAPK signaling pathway & $\begin{array}{l}\text { Involved in various cellular functions, including cell } \\
\text { proliferation, differentiation, and migration }\end{array}$ & $\begin{array}{l}\operatorname{miR}-31,-204,-335,-127,-34 b / c \\
-182,-150, \text { let- } 7 \mathrm{~d}\end{array}$ \\
\hline Wnt signaling pathway & $\begin{array}{l}\text { Involved in cell-fate specification, progenitor-cell } \\
\text { proliferation, cell division, cell adhesion, and motility }\end{array}$ & $\begin{array}{l}\operatorname{miR}-222,-542,-346,-200 \mathrm{c},-186 \\
-182,-150\end{array}$ \\
\hline VEGF signaling pathway & $\begin{array}{l}\text { Mediate the proliferation and migration of endothelial cells } \\
\text { and promote their survival and vascular permeability }\end{array}$ & miR-222 \\
\hline Notch signaling pathway & $\begin{array}{l}\text { Involved in cell proliferation, differentiation, apoptosis, } \\
\text { and mediate intercellular interactions }\end{array}$ & $\operatorname{miR}-449 a,-34 c$ \\
\hline TGF-beta signaling pathway & $\begin{array}{l}\text { Regulate cellular functions such as proliferation, } \\
\text { apoptosis, differentiation, and migration }\end{array}$ & miR-186, -154, -192 \\
\hline ErbB signaling pathway & $\begin{array}{l}\text { Regulate cellular functions such as proliferation, } \\
\text { differentiation, motility, and survival }\end{array}$ & $\operatorname{miR}-222,-200 \mathrm{c},-34 \mathrm{~b} / \mathrm{c},-150$ \\
\hline Insulin signaling pathway & $\begin{array}{l}\text { Associated with the MAPK pathway and } \\
\text { mitogenic responses, and involved in glycogen } \\
\text { synthesis and glucose uptake of cell }\end{array}$ & $\operatorname{miR}-338,-150,-346,-542,-34 b$ \\
\hline $\mathrm{T}$ cell receptor signaling pathway & Associated with cytokine production andthe immune system & miR-222, -150 \\
\hline Axon guidance & $\begin{array}{l}\text { Precisely regulate axons to reach their correct targets, } \\
\text { and important in neural development }\end{array}$ & $\begin{array}{l}\operatorname{miR}-134,-204,-222,-346,-200 c \\
-34 b,-181 a,-339,-23 a,-31\end{array}$ \\
\hline Focal adhesion & $\begin{array}{l}\text { Involved in cell motility, proliferation, differentiation, } \\
\text { survival, and regulation of gene expression }\end{array}$ & $\begin{array}{l}\operatorname{miR}-539,-134,-96,-455,-222,-542 \\
-200 c,-34 b / c,-23 a,-150,-338\end{array}$ \\
\hline Regulation of actin cytoskeleton & $\begin{array}{l}\text { Maintain cell architecture, and involved in cell motility, } \\
\text { differentiation, andintra-cellular transportation }\end{array}$ & $\begin{array}{l}\operatorname{miR}-96,-222,-363,-200 \mathrm{c},-182,-34 \mathrm{c}, \\
-23 \mathrm{a},-122,-338\end{array}$ \\
\hline ECM-receptor interaction & $\begin{array}{l}\text { Involved in cell adhesion, migration, differentiation, } \\
\text { proliferation, and apoptosis }\end{array}$ & miR-196a, $-96,-338$, let-7d \\
\hline Adherens junction & $\begin{array}{l}\text { Maintain tissue architecture and cell polarity, } \\
\text { and limit cell movement and proliferation }\end{array}$ & $\operatorname{miR}-455,449,186,34 \mathrm{c}, 328$ \\
\hline Cell adhesion molecules & $\begin{array}{l}\text { Involved in hemostasis, immune response, } \\
\text { inflammation, and development of neuronal tissue }\end{array}$ & $\operatorname{miR}-496$ \\
\hline
\end{tabular}

*Based on the KEGG pathway database (http://www.kegg.jp/kegg/pathway.html\#organismal). 


\section{DISCUSSION}

The present study compared the miRNA profiling of cutaneous wound tissue between STZ-induced diabetic rats and normal rats by microarray, and validated the microarray data by qRT-PCR assays. Eighty-three miRNAs were identified in STZ-induced diabetic wound samples, with 18 miRNAs upregulated and 65 downregulated. A previous study found that the expression of some specific miRNAs changed at a specific phase of wound healing, and the aberrant regulation of these specific miRNAs plays a key role in the abnormal healing of problem wounds (Shilo et al., 2007). Recent advances in the synthesis and chemistry of nucleic acids have allowed us to establish more efficient methods of performing miRNA-based therapies in vitro and in vivo, and multiple approaches of miRNA modulation have been used in clinical and experimental applications, with great success (Lanford et al., 2010; Hatziapostolou et al., 2011; Zhu et al., 2011; Creasey et al., 2014). Therefore, miRNA targeting alone, or in combination with conventional therapies, could be a new opportunity for diabetic wound healing, by reducing aberrantly expressed miRNA levels or by elevating beneficial miRNA levels. In addition, miRNA-based therapies provide a unique advantage, because by modulating a single miRNA a group of functionally related genes in a pathway can be targeted, in contrast to modulating a single gene at a time, as is the case with conventional gene therapy. In this regard, our study may provide a theoretical and experimental foundation for the further investigation of miRNA-based therapies, which may reveal a novel mechanism of impaired diabetic wound healing at the molecular level.

The enrichment analysis of the differentially expressed miRNAs showed that several miRNAs are involved in several KEGG pathways that can regulate the proliferation, differentiation, apoptosis, migration, and secretion of tissue repair cells, and are linked to inflammatory cells, the extracellular matrix, growth factors, and other relevant factors (Table 6). It has been reported that wound healing is tightly regulated by multiple factors, and any abnormal changes to these factors may impair optimum wound healing (Baum and Arpey, 2005). We suggest that differentially expressed miRNAs probably contribute to poor diabetic wound healing, and this requires further investigation.

We found that miR-331was upregulated in the cutaneous wounds of STZ-induced diabetic rats, whereas miR-425 was downregulated. miR-331 has been reported to target the mRNA of the enzyme deoxyhypusine hydroxylase, which can catalyze the activation of the eukaryotic translation initiation factor and thus inhibit cell proliferation (Epis et al., 2012). miR-425 has been reported to negatively regulate the atrial natriuretic peptide (Arora et al., 2013), which can inhibit multiple cell proliferation, indicating that expression alteration of both miRNAs may impair diabetic wound healing because they inhibit cell proliferation. miR484 suppresses the translation of the mitochondrial fission protein Fis1, and consequently inhibits Fis1-mediated fission and apoptosis in cardiomyocytes and adrenocortical cancer cells (Wang et al., 2012). miR-378 enhances cell survival and promotes angiogenesis by targeting Sufu and Fus 1 expression (Lee et al., 2007), and miR-30 inhibits mitochondrial fission and the consequent apoptosis by suppressing p53 expression (Li et al., 2010), and stimulates arteriolar branching by directly targeting the Notch ligand Delta-like 4 (Dll4) (Jiang et al., 2013). All of these miRNAs were downregulated in the cutaneous wounds of STZ-induced diabetic rats in our study, suggesting that alterations may contribute to impaired wound healing by increasing cell apoptosis and inhibiting angiogenesis. In addition, we found that miR-200 was downregu- 
lated in the experimental group, which was reported to be highly expressed in normal skin and was expected to positive regulate E-cadherin by specifically targeting ZEB1 and SIP1 (also known as ZEB2) (Gregory et al., 2008; Korpal et al., 2008) and thus was seemed to be essential in maintaining epithelial stability (Tunggal et al., 2005), suggesting that it has an inhibitory effect on diabetic wound healing.

In conclusion, this study has identified differentially expressed miRNAs in cutaneous wound tissue of STZ-induced diabetic rats using microarray analysis, and provides evidence that they are involved in the process of wound healing, which suggests that the alteration of these miRNAs may be a novel molecular mechanism of impaired diabetic wound healing. Together with the great progress that has been made in miRNA-based therapies, this study may provide a new method for the treatment of poor diabetic wound healing, once the relevant theories have been sufficiently elucidated. Nevertheless, our study only serves as a start toward a deeper understanding of the roles of miRNAs in diabetic wound healing. Their exact regulatory functions are still unclear, and how to perform miRNA-based therapy effectively and safely still needs further study.

\section{Conflicts of interest}

The authors declare no conflicts of interest.

\section{ACKNOWLEDGMENTS} and \#81060323).

Research supported by the National Natural Science Foundation of China (\#30560058

\section{REFERENCES}

Aberdam D, Candi E, Knight RA and Melino G (2008). miRNAs, 'stemness' and skin. Trends Biochem. Sci. 33: 583-591. Arora P, Wu C, Khan AM, Bloch DB, et al. (2013). Atrial natriuretic peptide is negatively regulated by microRNA-425. J. Clin. Invest. 123: 3378-3382.

Banerjee J and Sen CK (2013). MicroRNAs in skin and wound healing. Methods Mol. Biol. 936: 343-356.

Bartel DP (2009). MicroRNAs: target recognition and regulatory functions. Cell 136: 215-233.

Baum CL and Arpey CJ (2005). Normal cutaneous wound healing: clinical correlation with cellular and molecular events. Dermatol. Surg. 31: 674-686.

Cavanagh PR, Lipsky BA, Bradbury AW and Botek G (2005). Treatment for diabetic foot ulcers. Lancet 366: 1725-1735.

Creasey KM, Zhai J, Borges F, Van Ex F, et al. (2014). miRNAs trigger widespread epigenetically activated siRNAs from transposons in Arabidopsis. Nature 508: 411-415.

Epis MR, Giles KM, Kalinowski FC, Barker A, et al. (2012). Regulation of expression of deoxyhypusine hydroxylase $(\mathrm{DOHH})$, the enzyme that catalyzes the activation of eIF5A, by miR-331-3p and miR-642-5p in prostate cancer cells. J. Biol. Chem. 287: 35251-35259.

Gregory PA, Bert AG, Paterson EL, Barry SC, et al. (2008). The miR-200 family and miR-205 regulate epithelial to mesenchymal transition by targeting ZEB1 and SIP1. Nat. Cell Biol. 10: 593-601.

Hatziapostolou M, Polytarchou C, Aggelidou E, Drakaki A, et al. (2011). An HNF4 $\alpha$-miRNA inflammatory feedback circuit regulates hepatocellular oncogenesis. Cell 147: 1233-1247.

Huang DW, Sherman BT and Lempicki RA (2009a). Systematic and integrative analysis of large gene lists using DAVID bioinformatics resources. Nat. Protoc. 4: 44-57.

Huang DW, Sherman BT and Lempicki RA (2009b). Bioinformatics enrichment tools: paths toward the comprehensive functional analysis of large gene lists. Nucleic Acids Res. 37:1-13.

Jiang Q, Lagos-Quintana M, Liu D, Shi Y, et al. (2013). miR-30a regulates endothelial tip cell formation and arteriolar branching. Hypertension 62: 592-598. 
Korpal M, Lee ES, Hu G and Kang Y (2008). The miR-200 family inhibits epithelial-mesenchymal transition and cancer cell migration by direct targeting of E-cadherin transcriptional repressors ZEB1 and ZEB2. J. Biol. Chem. 283: 14910-14914.

Lanford RE, Hildebrandt-Eriksen ES, Petri A, Persson R, et al. (2010). Therapeutic silencing of microRNA-122 in primates with chronic hepatitis C virus infection. Science 327: 198-201.

Lee DY, Deng Z, Wang CH and Yang BB (2007). MicroRNA-378 promotes cell survival, tumor growth, and angiogenesis by targeting SuFu and Fus-1 expression. Proc. Natl. Acad. Sci. U. S. A. 104: 20350-20355.

Li J, Donath S, Li Y, Qin D, et al. (2010). miR-30 regulates mitochondrial fission through targeting p53 and the dynaminrelated protein-1 pathway. PLoS Genet. 6: e1000795.

Morain WD and Colen LB (1990). Wound healing in diabetes mellitus. Clin. Plast. Surg. 17: 493-501.

Shilo S, Roy S, Khanna S and Sen CK (2007). MicroRNA in cutaneous wound healing: a new paradigm. DNA Cell Biol. 26: 227-237.

Tunggal JA, Helfrich I, Schmitz A, Schwarz H, et al. (2005). E-cadherin is essential for in vivo epidermal barrier function by regulating tight junctions. EMBO J. 24: 1146-1156.

Wang K, Long B, Jiao JQ, Wang JX, et al. (2012). miR-484 regulates mitochondrial network through targeting Fis1. Nat. Commun. 3: 781.

Yi R, O'Carroll D, Pasolli HA, Zhang Z, et al. (2006). Morphogenesis in skin is governed by discrete sets of differentially expressed microRNAs. Nat. Genet. 38: 356-362.

Zhu H, Hu F, Wang R, Zhou X, et al. (2011). Arabidopsis Argonaute10 specifically sequesters miR166/165 to regulate shoot apical meristem development. Cell 145: 242-256. 